$$
\begin{aligned}
& \text { 일개 대학병원의 항생제 사용 실태 및 } \\
& \text { 주요 병원감염균주의 항생제 내성과의 상관 관계 }
\end{aligned}
$$

\title{
Relationship between Antibiotic Use and Antibiotic Resistance in Major Nosocomial Pathogens at a University Hospital
}

\author{
Young A Song, Sook-In Jung*, Mi Ok Chang, Hee-Jung Ban, Nam Chul Jin, \\ Hee Kyung Kim, Kyung Hwa Park, Jong Hee Shin ${ }^{1}$ and Sang Yeol Bae ${ }^{2}$ \\ Departments of Internal Medicine and ${ }^{1}$ Laboatory Medicine, Chonnam National University Medical School and \\ ${ }^{2}$ Medical Record Room, Chonnam National University Hospital, Gwangiu, Korea
}

This study was performed to evaluate the prescribing pattern of antibiotics and the relationship between antibiotic use and antibiotic resistance in major nosocomial pathogens at a university hospital in Korea. Data on annual patient-days and annual consumption (defined daily dose (DDD)/1,000 patient-days) of all antibiotics from 2000 to 2006 were analyzed. The antibiotic resistance in major nosocomial pathogens was determined by disc diffusion or automated systems. Spearman's correlation coefficient was used to determine the relationship between antibiotic use and resistance. Increasing trend on incidences of Klebsiella pneumoniae causing nosocomial bloodstream infections was noted from 2000 to 2006 ( $r=0.786, p=0.036$ ). Even though the annual patient-days of the hospital did not change $(r=-0.107, p=0.819)$, the annual usage of antibiotics significantly increased from 2000 to 2006 ( $r=0.929, p=0.003)$. A significant stepwise increase in consumption $(r>0.72$ and $p<0.05)$ was found for several broad-spectrum antibiotics such as ceftriaxone, piperacillin/tazobactam, imipenem, and vancomycin. The rise in piperacillin/tazobactam-resistant Serratia marcenscens $(r=0.893, p=0.007)$ and piperacillin/tazobactam-resistant Pseudomonas aeruginosa $(r=1.000$, $\mathrm{p}=0.000$ ) was significantly correlated with increased consumption of piperacillin/tazobactam respectively. Increased ciprofloxacin-resistant $S$. marcescens was significantly associated with increased usage of ciprofloxacin ( $r=0.919, p=0.003)$. This study demonstrated the significant changes in antibiotic use and positive relationship between antibiotic use and antibiotic resistance in several nosocomial pathogens. Continuous surveillance of antibiotic use is needed to encourage appropriate use of antibiotics and to reduce antibiotics resistance.

Keywords: Anti-bacterial agents; Utilization; Vascular resistance; Hospitals 


\section{서 론}

항생제의 개발로 감염증에 의한 사망이 현저하게 감소하 였으나, 부적절한 항생제의 사용은 내성균의 출현과 이로 인 한 의료비의 증가 및 입원 기간의 연장 등 의료 및 사회경제 적인 문제를 야기하기도 한다. ${ }^{1}$ 특히 우리나라는 항생제의 과다 사용 및 체계적인 관리 부족으로 항생제 내성균의 발 현율이 높은 것으로 알려져 있다. ${ }^{2}$ 항생제 내성은 지역사회 감염에 비해 병원성 감염에서 더욱 문제시 되고 있다. 따라 서 부적절한 항생제 사용을 줄이고 합리적인 사용을 통해 항생제 내성률을 감소시키기 위해서는 병원 내의 항생제 사 용에 대한 정확한 실태 파악과 변화 추이 및 주요 병원성 균 주의 항생제 내성 경향의 관찰이 필요하다. ${ }^{3,4}$ 본 연구에서는 최근 7년간 국내 일개 대학병원의 혈액에서 분리된 주요 병 원감염균주의 내성률과 항생제 사용량을 연도별로 분석하 고, 그 상관관계를 규명하고자 하였다.

\section{대상 및 방법}

\section{1. 주요 병원감염균주의 병원성 혈액감염률과 내성 경향}

2000년 1월 1일부터 2006년 12월 31일까지 7년 동안 전 남대학교병원에서 발생한 주요 병원감염균주의 병원성 혈류 감염률을 10,000 patient-days 당 분리 건수로 표시하였다. 병원에서 발생한 혈류감염률만을 구하기 위해 입원 48시간 이후에 시행한 혈액배양검사에서 동정된 균주만을 선별하였 고, 동일인에서 반복적으로 같은 균주가 동정되는 경우에는 항생제 감수성 결과가 같은 경우 그중 1 균주 만을 선별하여 연구에 포함시켰다. 주요 병원감염균주로는 그람음성균주 중 Escherichia coli, Klebsiella pneumoniae, Enterobacter species, Serratia marcescens, Pseudomonas aeruginosa, Acinetobacter baumannii를 대상으로 하였고, 그람양성균주에서는 Staphylococcus aureus를 대상으로 하였다. 항생제 감수성 검사는 2000년부터 2003년까지 분리된 균주는 디스크 확산 법을 이용하였고, 2004년부터 2006년까지 분리된 균주는 VITEK 2 (bioMerieux, Marcy-L'Etoile, France)와 Microscan (Dade Microscan Inc, West Sacramento, CA, USA)을 이용하였다.

\section{2. 항생제 사용량 분석}

2000년 1월 1일부터 2006년 12월 31일까지 7년 동안 전
남대학교병원의 입원 환자에서 사용한 모든 항생제를 대상으 로 사용량을 분석하였다. 각 항생제의 사용량 분석을 위해 병 원의 연도별 재원연인원수와 연도별 입원 환자의 시럽이나 과립을 제외한 경구 및 주사용 항생제의 사용량을 의무기록 실에 요청하여 취합하였다. 항생제의 사용량은 세계 보건기 구(World Health Organization, WHO)의 ATC (Anatomical therapeutic chemical classification system)에서 제 시하는 DDD (defined daily dose)를 이용하여 DDD/1,000 patient-days로 환산하여 비교하였다. ${ }^{5} \mathrm{DDD}$ 가 정의되어 있 지 않은 항생제에 대해서는 일반적인 상용량을 바탕으로 연 구자들 간에 합의하에 $\mathrm{DDD}$ 를 정하였다.

\section{3. 통계분석}

통계분석은 SPSS 14.0 프로그램을 이용하였다. Spearman 상관관계 분석을 이용하여 연도별 항생제 사용량의 변화와 연도별 균주의 내성률 변화 및 항생제 사용량과 균주별 내 성률 간의 상관관계를 분석하였다. $\mathrm{r}$ 값이 0.72 를 초과하거나 -0.72 미만이고 $\mathrm{p}$ 값이 0.05 미만인 경우에서 유의성이 있 는 것으로 판정하였다.

\section{결 과}

\section{1. 주요 병원감염균주의 연도별 병원성 혈류감염률}

주요 병원 감염균주의 연도별 병원성 혈류감염률은 Fig. 1

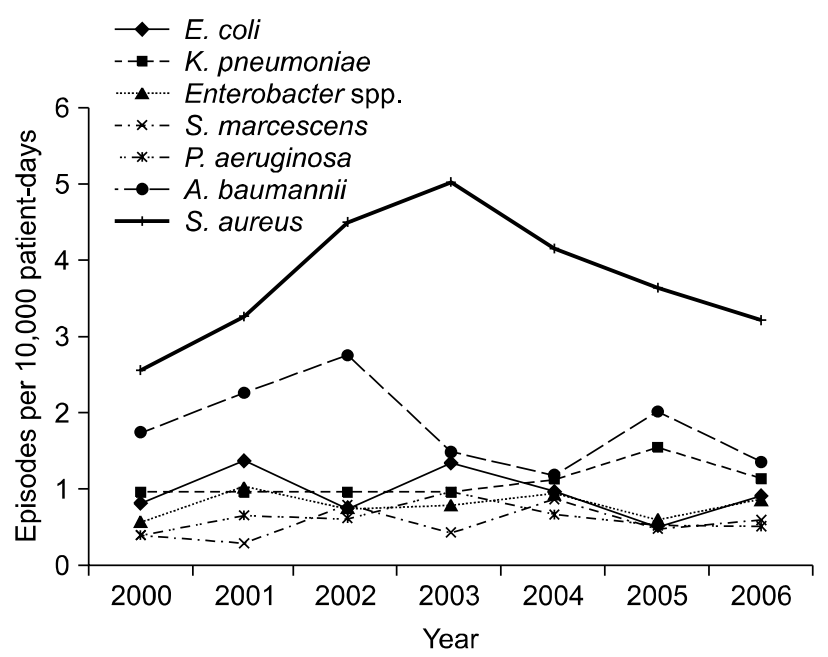

Fig. 1. Incidence (episodes per 10,000 patient-days) of nosocomial bloodstream infection caused by major nosocomial pathogens from patients treated at Chonnam National University Hospital in Korea from $2000 \sim 2006$. 
Table 1. Trends of resistance rates among major nosocomial pathogens causing nosocomial bloodstream infections at Chonnam National University Hospital, $2000 \sim 2006$

\begin{tabular}{|c|c|c|c|c|c|c|c|c|c|}
\hline \multirow{2}{*}{ Organism/antimicrobial agent } & \multicolumn{7}{|c|}{ Antimicrobial resistance (\%) by year } & \multicolumn{2}{|c|}{ Correlation } \\
\hline & 2000 & 2001 & 2002 & 2003 & 2004 & 2005 & 2006 & r & $p$ \\
\hline \multicolumn{10}{|l|}{ Escherichia coli } \\
\hline No. of isolates & 23 & 48 & 27 & 48 & 32 & 16 & 29 & & \\
\hline Ciprofloxacin & 17.4 & 34.0 & 29.6 & 43.8 & 32.3 & 50.0 & 48.3 & 0.786 & $0.036^{*}$ \\
\hline Cefotaxime & 4.3 & 14.9 & 18.5 & 17.7 & 3.2 & 18.8 & 31.0 & 0.607 & 0.148 \\
\hline Ceftazidime & 4.3 & 12.8 & 18.5 & 8.3 & 6.5 & 18.8 & 31.0 & 0.679 & 0.094 \\
\hline Piperacillin/tazobactam & 0 & 4.3 & 7.4 & 6.3 & 0 & 0 & 3.4 & -0.185 & 0.691 \\
\hline Gentamicin & 21.7 & 29.8 & 22.2 & 29.2 & 19.4 & 31.3 & 41.4 & 0.536 & 0.215 \\
\hline \multicolumn{10}{|l|}{ Klebsiella pneumoniae } \\
\hline No. of isolates & 27 & 33 & 35 & 34 & 37 & 49 & 36 & & \\
\hline Ciprofloxacin & 18.5 & 6.0 & 2.9 & 2.9 & 37.8 & 34.7 & 41.7 & 0.631 & 0.129 \\
\hline Cefotaxime & 37.0 & 24.1 & 17.1 & 11.8 & 45.9 & 49.0 & 33.3 & 0.321 & 0.482 \\
\hline Ceftazidime & 37.0 & 30.3 & 25.7 & 14.7 & 45.9 & 55.1 & 44.4 & 0.536 & 0.215 \\
\hline Piperacillin/tazobactam & 11.0 & 9.1 & 8.6 & 8.8 & 8.1 & 16.3 & 91.7 & 0.321 & 0.482 \\
\hline Gentamicin & 14.8 & 30.3 & 20.0 & 23.5 & 43.2 & 48.0 & 33.3 & 0.786 & $0.036^{*}$ \\
\hline \multicolumn{10}{|l|}{ Enterobacter species } \\
\hline No. of isolates & 16 & 36 & 27 & 28 & 31 & 19 & 27 & & \\
\hline Ciprofloxacin & 6.3 & 2.8 & 7.4 & 3.6 & 9.7 & 10.5 & 7.4 & 0.649 & 0.115 \\
\hline Cefotaxime & 37.5 & 38.9 & 29.6 & 32.1 & 31.0 & 31.6 & 44.4 & 0.036 & 0.939 \\
\hline Ceftazidime & 56.3 & 41.7 & 33.3 & 28.6 & 45.2 & 31.6 & 55.6 & -0.179 & 0.702 \\
\hline Piperacillin/tazobactam & 18.8 & 22.2 & 14.8 & 10.7 & 20.6 & 15.8 & 18.5 & -0.250 & 0.589 \\
\hline Gentamicin & 50.0 & 19.4 & 25.9 & 28.6 & 19.4 & 21.1 & 18.5 & -0.631 & 0.129 \\
\hline Amikacin & 12.5 & 94.4 & 96.3 & 92.9 & 6.5 & 0 & 3.7 & -0.714 & 0.071 \\
\hline \multicolumn{10}{|l|}{ Serratia marcescens } \\
\hline No. of isolates & 11 & 10 & 29 & 15 & 29 & 15 & 19 & & \\
\hline Ciprofloxacin & 0 & 10.0 & 6.9 & 20.0 & 10.3 & 20.0 & 15.8 & 0.757 & $0.049^{*}$ \\
\hline Cefotaxime & 9.0 & 20.0 & 37.9 & 20.0 & 58.6 & 53.3 & 68.4 & 0.901 & $0.006^{*}$ \\
\hline Piperacillin/tazobactam & 9.0 & 10.0 & 24.1 & 13.3 & 51.7 & 33.3 & 57.9 & 0.929 & $0.003^{*}$ \\
\hline Gentamicin & 18.0 & 50.0 & 58.6 & 20.0 & 69.0 & 66.7 & 73.7 & 0.859 & $0.014^{*}$ \\
\hline Amikacin & 9.0 & 90.0 & 100 & 100 & 58.6 & 46.7 & 52.6 & -0.090 & 0.848 \\
\hline \multicolumn{10}{|l|}{ Pseudomonas aeruginosa } \\
\hline No. of isolates & 11 & 23 & 22 & 35 & 22 & 17 & 16 & & \\
\hline Ciprofloxacin & 18.2 & 34.8 & 13.6 & 20.0 & 59.1 & 11.8 & 31.3 & 0.036 & 0.939 \\
\hline Ceftazidime & 45.5 & 17.4 & 13.6 & 11.4 & 18.2 & 23.5 & 50.0 & 0.321 & 0.482 \\
\hline Piperacillin/tazobactam & - & - & - & - & 22.7 & 25.0 & 37.5 & 1.000 & $0.000^{*}$ \\
\hline Imipenem & 0 & 30.4 & 13.6 & 8.6 & 13.6 & 11.8 & 37.5 & 0.432 & 0.333 \\
\hline Amikacin & 27.3 & 34.8 & 18.2 & 17.1 & 50.0 & 11.8 & 11.8 & -0.595 & 0.159 \\
\hline \multicolumn{10}{|l|}{ Acinetobacter baumannii } \\
\hline No. of isolates & 49 & 79 & 100 & 53 & 39 & 64 & 43 & & \\
\hline Ciprofloxacin & 47.1 & 35.4 & 38.6 & 12.7 & 13.6 & 22.0 & 16.0 & -0.643 & 0.119 \\
\hline Ceftazidime & 64.7 & 60.8 & 65.3 & 20.9 & 14.4 & 21.4 & 18.1 & -0.714 & 0.071 \\
\hline Imipenem & 13.7 & 15.2 & 5.0 & 1.5 & 3.2 & 4.9 & 2.1 & -0.786 & 0.071 \\
\hline Amikacin & 64.7 & 51.9 & 56.4 & 16.4 & 9.6 & 20.3 & 14.6 & -0.786 & $0.036 *$ \\
\hline \multicolumn{10}{|l|}{ Staphylococcus aureus } \\
\hline No. of isolates & 72 & 114 & 163 & 179 & 137 & 115 & 102 & & \\
\hline Oxacillin & 64.9 & 70.7 & 78.8 & 81.0 & 83.2 & 83.5 & 79.4 & 0.786 & $0.036^{*}$ \\
\hline Ciprofloxacin & 58.3 & 60.5 & 70.5 & 74.2 & 66.3 & 66.1 & 64.7 & 0.321 & 0.482 \\
\hline Erythromycin & 68.9 & 80.2 & 82.4 & 79.3 & 78.1 & 77.4 & 74.5 & -0.214 & 0.645 \\
\hline Clindamycin & 56.8 & 64.7 & 71.5 & 66.5 & 67.2 & 70.4 & 66.7 & 0.536 & 0.215 \\
\hline
\end{tabular}

*Stastically significant association $(p<0.05)$. 
과 같다. K. pneumoniae에 의한 병원성 혈류감염 발생률은 2000년도에 0.96/10,000 patient-days에서 2006년도에 1.14 $/ 10,000$ patient-days로 1.2 배 증가하였다 $(\mathrm{r}=0.786, \mathrm{p}=$ 0.036). 주요 병원 감염균주 중 S. aureus에 의한 병원성 혈 류감염률이 가장 높았고, 2000년도에 2.56/10,000 patientdays에서 2003년도에 5.01/10,000 patient-days까지 증가 하였다가 2006년도에는 3.22/10,000 patient-days로 다시 감소하였다 $(\mathrm{r}=0.143, \mathrm{p}=0.760)$. 그 외 Enterobacter spp., S. marcescens와 P. aeruginosa는 2000년도에 비해 2006년 도에 병원성 혈류감염률이 증가하는 추세였으나 통계적으로 의미 있는 증가는 아니었다 $(\mathrm{p}=0.702, \mathrm{p}=0.180, \mathrm{p}=0.939)$.

\section{2. 병원성 혈류감염을 일으킨 주요 병원감염균주의 내성 경향}

병원성 혈류감염을 일으킨 주요 병원감염균주의 감수성 성적은 Table 1 과 같다. 주요 병원성 그람음성균주의 2006 년도 ciprofloxacin 내성은 E. coli, K. pneumoniae, P. aeruginosa에 대해 각각 $48.3 \%, 41.7 \%, 31.3 \%$ 였고, E. coli의 ciprofloxacin 내성은 연도별로 증가하는 경향을 보였다 $(\mathrm{r}=$ 0.786, $\mathrm{p}=0.036$ ). Enterobacter spp.는 ciprofloxacin 내성은 $7.4 \%$ 로 비교적 낮게 유지되는 반면, cefotaxime과 ceftazidime 내성은 각각 $44.4 \%$ 과 $55.6 \%$ 로 높았다. S. marcescens 의 ciprofloxacin 내성은 2000년도에 $0 \%$ 에서 2006년도에 $15.8 \%$ 로 증가하였고 $(\mathrm{r}=0.757, \mathrm{p}=0.049)$, cefotaxime 내성 은 $9 \%$ 에서 $68.4 \%$ 로 7.6 배 증가하였다 $(r=0.901, p=0.006)$. 또한 piperacillin/tazobactam 내성은 2000년도에 9\%에서 2006년도에 57.9\%로 증가하였고(r=0.929, p=0.003), gentamicin에 대한 내성 역시 통계학적으로 유의하게 연도별로 증가하였다 $(\mathrm{r}=0.859, \mathrm{p}=0.014)$. P. aeruginos $a$ 의 piperacillin/ tazobactam과 imipenem 내성은 2006년도에 각각 $37.5 \%$ 로 광범위 항생제에 높은 내성률을 보였다. 그람양성균주 중 에서 S. aureus의 oxacillin 내성은 2000년도에 $64.9 \%$ 에서 2006년도에 $79.4 \%$ 로 전반적으로 증가하는 경향을 보였다 $(\mathrm{r}=0.786, \mathrm{p}=0.036)$. S. aureus 는 ciprofloxacin, erythromycin, clindamycin에 각각 $64.7 \%, 74.5 \%, 66.7 \%$ 로 높은 내성률을 보였다.

\section{3. 연도별 항생제 사용량의 변화}

\section{1. 연도별 재원연인원수와 항생제 사용량}

2000년부터 2006년까지 전남대학교병원의 연도별 재원 연인 원수의 분포는 변화가 없었으나 $(r=-0.107, p=0.819)$, 항생제 총 사용량은 증가하는 경향을 보였다 $(\mathrm{r}=0.929, \mathrm{p}=0.003)$.

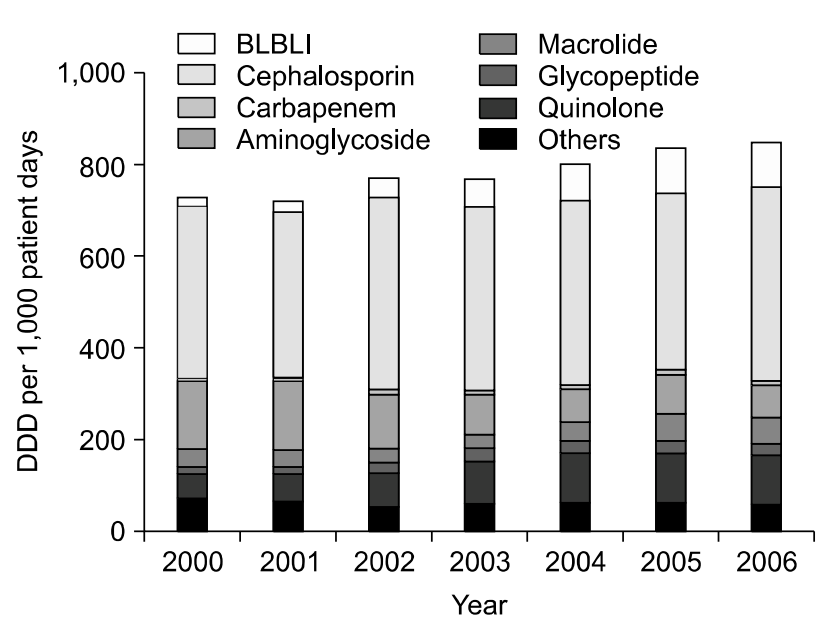

Fig. 2. Annual consumption and proportional use of several representative classes of antimicrobial agents at Chonnam National University Hospital in Korea, $2000 \sim 2006$. BLBLI, $\beta$-lactam/ $\beta$-lactamase inhibitor.

\section{2. 항생제 계열별 사용량의 변화}

항생제 계열별 사용량의 연도별 분포는 Fig. 2 와 같다. 각 연도별로 cephalosporin 계열 항생제의 사용 비율이 가장 높았 으며(46.1 54.5\%), aminoglycoside 계열과(8.3 21.3\%) quinolone 계열의(7.1 13.5\%) 순으로 항생제 사용 비율이 높았 다. Quinolone계열과 $\beta$-lactam/ $\beta$-lactamase inhibitor계열은 2000년도에 비해 2006년도의 항생제 사용량이 각각 2.1배와 5.6 배 증가하였고, 연도별로 사용량이 증가하는 경향을 보였다 $(\mathrm{r}=0.857, \mathrm{p}=0.014 ; \mathrm{r}=1.000, \mathrm{p}=0.000)$. 반면 aminoglycoside계열은 2000년도에 $149.31 \mathrm{DDD} / 1,000$ patient-days에 서 2006년도에 $70.52 \mathrm{DDD} / 1,000$ patients-days로 감소하는 경향을 보였다 $(\mathrm{r}=-0.929, \mathrm{p}=0.003)$.

\section{3. 주요 단일 항생제별 사용량의 변화}

본 병원에서 사용되는 주요 항생제별 사용량의 변화는 Table 2와 같다. 3세대 cephalosporin 중 ceftriaxone과 ceftizoxime의 사용량이 연도별로 증가하였다 $(\mathrm{r}=0.964$, $\mathrm{p}=0.000 ; \mathrm{r}=1.000, \mathrm{p}=0.000$ ). Piperacillin/tazobactam은 2000년도에 비해 2006년도에 사용량이 38.1배 증가하였고, imipenem은 2002년도부터 사용되기 시작하여 2006년도에 54.3 배 증가하였다. Piperacillin/tazobactam과 imipenem의 연도별 사용량도 증가하였다 $(r=0.964, p=0.000 ; r=0.955$, $\mathrm{p}=0.001$ ). Vancomycin은 2000년도에 $5.65 \mathrm{DDD} / 1,000$ patient-days에 2006년도에 $17.33 \mathrm{DDD} / 1,000$ patientdays로 증가하였고, 연도별로도 사용량이 증가하는 경향을 보였다(r=0.929, $\mathrm{p}=0.003)$. 반면 amikacin과 astromicin 
Table 2. Annual consumption of several representative antimicrobial agents at Chonnam National University Hospital, $2000 \sim 2006$

\begin{tabular}{|c|c|c|c|c|c|c|c|c|c|}
\hline \multirow{2}{*}{ Antimicrobial agent } & \multicolumn{7}{|c|}{ Antibiotic consumption (DDD/1000 patient-days) by year } & \multicolumn{2}{|c|}{ Correlation } \\
\hline & 2000 & 2001 & 2002 & 2003 & 2004 & 2005 & 2006 & r & $\mathrm{p}$ \\
\hline Piperacillin/tazobactam & 0.73 & 0.59 & 0.83 & 2.94 & 13.44 & 25.50 & 27.82 & 0.964 & $0.000^{*}$ \\
\hline Cefoperazone/sulbactam & 0.00 & 0.00 & 0.48 & 13.65 & 7.45 & 1.53 & 3.27 & 0.667 & 0.102 \\
\hline cefotaxime & 29.12 & 39.02 & 49.12 & 53.60 & 56.65 & 44.12 & 27.25 & 0.036 & 0.939 \\
\hline Ceftriaxone & 0.00 & 5.05 & 6.97 & 8.53 & 10.28 & 9.33 & 34.37 & 0.964 & $0.000^{*}$ \\
\hline Ceftizoxime & 9.84 & 21.35 & 22.76 & 26.28 & 29.14 & 37.12 & 55.67 & 1.000 & $0.000^{*}$ \\
\hline Ceftazidime & 6.24 & 8.17 & 10.23 & 12.67 & 6.91 & 7.47 & 5.96 & -0.286 & 0.535 \\
\hline Cefepime & 1.85 & 1.26 & 2.78 & 4.57 & 3.96 & 1.07 & 1.15 & -0.321 & 0.482 \\
\hline Imipenem & 0.00 & 0.00 & 0.11 & 5.30 & 5.34 & 8.46 & 5.97 & 0.955 & $0.001^{*}$ \\
\hline Meropenem & 1.68 & 1.13 & 9.92 & 3.68 & 3.40 & 2.85 & 3.22 & 0.286 & 0.535 \\
\hline Amikacin & 25.40 & 18.62 & 16.41 & 10.29 & 4.54 & 3.63 & 3.43 & -1.000 & $0.000^{*}$ \\
\hline Astromicin & 33.74 & 53.00 & 30.87 & 15.23 & 11.97 & 9.90 & 8.64 & -0.964 & $0.000^{*}$ \\
\hline Netilmicin & 28.54 & 27.33 & 30.05 & 17.26 & 18.96 & 18.97 & 18.27 & -0.643 & 0.119 \\
\hline Isepacin & 32.15 & 27.32 & 28.19 & 34.20 & 25.03 & 40.13 & 27.57 & 0.036 & 0.939 \\
\hline Vancomycin & 5.65 & 5.64 & 10.82 & 16.41 & 15.45 & 16.71 & 17.33 & 0.929 & $0.003^{*}$ \\
\hline Teicoplanin & 9.35 & 9.19 & 9.74 & 11.68 & 10.27 & 11.00 & 7.77 & 0.107 & 0.819 \\
\hline Ciprofloxacin & 30.07 & 42.29 & 58.32 & 76.16 & 70.17 & 74.28 & 63.56 & 0.679 & 0.094 \\
\hline Levofloxacin & 9.22 & 8.10 & 8.73 & 4.71 & 3.31 & 7.69 & 6.64 & -0.679 & 0.094 \\
\hline Clindamycin & 26.72 & 18.87 & 13.26 & 14.63 & 18.78 & 21.21 & 26.50 & 0.036 & 0.939 \\
\hline Metronidazole & 4.02 & 3.96 & 3.59 & 5.20 & 5.85 & 7.25 & 9.12 & 0.857 & $0.014^{*}$ \\
\hline
\end{tabular}

*Statistically significant association $(p<0.05)$.

Table 3. Relationship between annual consumption of individual antibiotics and rates of resistant Gram-negative pathogens causing nosocomial bloodstream infections at Chonnam National University Hospital, 2000 2006

\begin{tabular}{|c|c|c|c|c|c|c|c|c|c|c|c|c|}
\hline \multirow[t]{2}{*}{ Antimicrobial agent } & \multicolumn{2}{|c|}{ Escherichia coli } & \multicolumn{2}{|c|}{$\begin{array}{c}\text { Klebsiella } \\
\text { pneumoniae }\end{array}$} & \multicolumn{2}{|c|}{$\begin{array}{l}\text { Enterobacter } \\
\text { species }\end{array}$} & \multicolumn{2}{|c|}{$\begin{array}{c}\text { Serratia } \\
\text { marcescens }\end{array}$} & \multicolumn{2}{|c|}{$\begin{array}{c}\text { Pseudomonas } \\
\text { aeruginosa }\end{array}$} & \multicolumn{2}{|c|}{$\begin{array}{c}\text { Acinetobacter } \\
\text { baumannii }\end{array}$} \\
\hline & r & $p$ & r & $p$ & $r$ & $p$ & $r$ & $p$ & $r$ & $p$ & $r$ & $p$ \\
\hline Ciprofloxacin & 0.679 & 0.094 & 0.036 & 0.939 & 0.378 & 0.403 & 0.919 & $0.003^{*}$ & -0.071 & 0.879 & -0.857 & 0.014 \\
\hline Cefotaxime & -0.429 & 0.337 & -0.107 & 0.819 & -0.786 & 0.036 & 0.054 & 0.908 & - & - & - & - \\
\hline Ceftazidime & -0.071 & 0.879 & -0.679 & 0.094 & -0.857 & 0.014 & - & - & -0.964 & 0.000 & 0.321 & 0.482 \\
\hline Piperacillin/tazobactam & -0.296 & 0.518 & 0.375 & 0.432 & -0.321 & 0.482 & 0.893 & $0.007^{*}$ & 1.000 & $0.000^{*}$ & - & - \\
\hline Imipenem & - & - & - & - & - & - & - & - & 0.200 & 0.667 & -0.667 & 0.102 \\
\hline Amikacin & - & - & - & - & 0.714 & 0.071 & 0.090 & 0.848 & 0.595 & 0.159 & 0.786 & $0.036^{*}$ \\
\hline
\end{tabular}

*Stastically significant association $(r>0.72$ or $<-0.72, p<0.05)$.

은 연도별로 사용량이 감소하였다 $(\mathrm{r}=-1.000, \mathrm{p}=0.000$; $\mathrm{r}=-0.964, \mathrm{p}=0.001)$.

\section{4. 항생제 사용량과 내성의 상관 관계}

단일 항생제의 사용량과 병원성 혈류감염을 일으킨 주요 병원감염균주의 내성률과의 상관 관계는 Table 3과 같다. Ciprofloxacin의 사용량과 S. marcescens의 ciprofloxacin 내성과는 양의 상관 관계가 있었다 $(\mathrm{r}=0.919, \mathrm{p}=0.003)$. $\mathrm{Pi}-$ peracillin/tazobactam의 사용량도 S. marcescens의 piperacillin/tazobactam 내성과 양의 상관 관계가 있었다 $(\mathrm{r}=$ $0.893, \mathrm{p}=0.007)$. 또한 P. aeruginosa의 piperacillin/tazo- bactam 내성은 piperacillin/tazobactam의 사용량과 양의 상관 관계를 보였고 $(\mathrm{r}=1.000, \mathrm{p}=0.000), \mathrm{A}$. baumannii의 amikacin 내성은 amikacin의 사용량과 양의 상관 관계를 보였다 $(\mathrm{r}=0.786, \mathrm{p}=0.036)$.

Enterobacter spp.의 ciprofloxacin 내성과 S. marcescens 의 cefotaxime 내성은 quinolone계 항생제의 사용량과 양 의 상관 관계가 있었다 $(\mathrm{r}=0.757, \mathrm{p}=0.049 ; \mathrm{r}=0.829, \mathrm{p}=$ 0.021). S. marcescens의 piperacillin/tazobactam 내성은 cephalosporin계열의 사용량과 양의 상관 관계가 있었고 $(\mathrm{r}=0.786, \mathrm{p}=0.036)$, S. marcenscens 와 $P$. aeruginos $a$ 의 piperacillin/tazobactam 내성은 $\beta$-lactam/ $\beta$-lactamase inhi- 
bitor계열의 사용량과 양의 상관 관계가 있었다 $(\mathrm{r}=0.929$, $\mathrm{p}=0.003 ; \mathrm{r}=1.000, \mathrm{p}=0.000$ ).

\section{고 찰}

본 연구는 한 대학병원의 7년간 항생제 사용 실태와 혈액 에서 분리되는 주요 병원감염균주의 항생제 내성 양상을 분 석하고 그 상관 관계를 규명하고자 시행되었다. 항생제 사용 실태에 관한 연구로는 국내에서는 김 등 ${ }^{6}$ 이 건강보험청구자 료를 바탕으로 국내 항생제 사용량을 진료형태별, 의료기관 종별 및 지역별로 분석한 바가 있다. 타 연구에서는 국내 5 개 3 차 병원의 $\beta$-lactam계 항생제 사용 실태와 $K$. pneumoniae의 항생제 내성이 상관관계가 있음을 보고하였 다. ${ }^{7}$ 또한 윤 등 ${ }^{8}$ 은 일개 대학병원에서 39 개월간의 항생제 사용량과 분리 균주의 항생제 내성률을 시계열 분석하여 상 관관계를 규명하였다. 항생제 사용 실태와 병원감염의 원인 균주의 내성률을 분석하고 이를 기반으로 항생제 처방 프로 그램의 개선하거나 제한 항생제 적용 또는 의료인의 교육을 통한 효과적인 관리를 위해서는 개별 의료기관에 따른 접근 이 필요하여 시간 경과에 따른 변화 추이를 관찰하는 것이 필요하다.

본 연구의 결과에 따르면 S. aureus에 의한 병원성 혈류 감염률이 주요 그람음성균주에 의한 감염률에 비해 높았다. 그람음성균주 중에서는 A. baumannii에 의한 감염률이 가 장 높았고, K. pneumonaie, E. coli의 순이었다 미국의 SCOPE (Surveillance and Control of Pathogens of Epidmiological Importance) 사업에 의하면 1995년부터 2002 년까지 미국 전역의 49 개 병원을 대상으로 조사한 결과 병 원성 혈류 감염의 주요 원인 균으로 Coagulase negative Staphylococci (CoNS) (31.3\%)의 빈도가 가장 높았고, S, aureus (20\%), Enterococcus spp. (9.4\%), Candida spp. $(9.0 \%)$ 순이었다. 그람음성균주 중에서는 E. coli $(5.6 \%)$, Klebsiella spp. (4.8\%), P. aeruginosa (2.1\%), Enterobacter spp. (3.9\%), Serratia spp. (1.7\%), A. baumannii (1.3\%) 의 순으로 본 연구의 결과와는 발생 빈도 순에 차이가 있었 다. ${ }^{9}$ 또한 2002년도에 수행된 국내의 연구에서는 병원 혈류 감염균의 빈도는 S. aureus (20.7\%), E. coli (17.5\%), P. aeruginosa $(14.7 \%)$ 순이었다. ${ }^{10}$ 이는 각 병원의 특성과 이 에 따른 주요 병원감염균주의 분포 및 빈도의 차이에 의한 것으로 생각한다. 또한 본 연구에서는 $\mathrm{CoNS}$ 를 분석에서 제
외하였는데, 균주가 분리된 각 환자의 임상 양상에 대한 분 석 없이 미생물학적으로 동정된 균주의 데이터를 대상으로 한 감시 연구이므로 오염균이나 상재균이 포함되는 경우 실 제 병원성 혈류감염을 제대로 반영하지 못할 가능성을 고려 하여 분석에서 제외하였다.

연도별로 주요 병원성 감염 균주의 내성은 전반적으로 증 가하는 경향을 보였다. 특히 그람음성균주 중에서 E. coli의 ciprofloxacin 내성, S. marcescens의 ciprofloxacin, cefotaxime, piperacillin/tazobactam 내성이 증가하였고, $P$. aeruginosa의 piperacillin/tazobactam 내성 빈도가 연도별로 증가하였다. 그람양성균주 중에서는 MRSA가 2000년 $64.9 \%$ 에 비해 2006년 $79.4 \%$ 로 1.2 배 증가하였다. 이는 미국 에서 병원성 혈류감염증 중 S. aureus의 methicillin 내성률인 $41.1 \%$ 와 중환자실 환자의 혈액에서 분리된 S. aureus의 methicillin 내성률 $44.1 \%$ 에 비해 높다. ${ }^{9}$ 반면 국내에서는 12 개 병원의 임상검체에서 분리된 S. aureus의 methicillin 내성 률은 2005년도에 65\%, 2006년도에 72\%로 본 연구와 유사 한 결과를 보였다. ${ }^{11}$ 그러나 언급된 다기관 연구에서는 지역사 회 감염 균주와 병원성 감염 균주가 분리되지 않았고, 혈액을 포함한 임상검체에서 분리된 균주의 항생제 내성률을 조사하 였으므로 본 연구의 결과와는 차이가 있다.

본 연구에서는 7 년간 3 차 병원에서의 항생제 사용량을 계 열별, 단일 항생제별로 분석하였으며, 재원 연인원수는 크게 변화가 없었으나 총 항생제 사용량과 quinolone, $\beta$-lactam/ $\beta$-lactamase inhibitor의 사용량이 크게 증가하였다. 단일 항생제 중에는 piperacillin/tazobactam, ceftriaxone, ceftrizoxime, imipenem, vancomycin, metronidazole 등의 광범 위 항생제의 사용량이 주로 증가하였다. 광범위 항생제 사용 은 심각한 병원 감염의 경험적 치료에 있어 중요한 역할을 하지만 항생제 내성균의 증가와 다제 내성 균주의 출현, 의 료비의 상승과 관련이 있다. ${ }^{12} \mathrm{Du}$ 등 $^{13}$ 의 연구에서는 3 세대 cephalosporin에 대한 사용 제한이 감염과 관련된 병원 내 사망률을 줄이고 항생제 감수성을 향상시켜 비용 절감 효과 를 보였다. 따라서 제한 항균제 시스템의 적극적인 활용과 항생제 사용에 대한 지속적인 감시 프로그램을 통해 배양 결과에 근거한 항생제의 사용과 병원과 지역 환경, 내성 경 향의 분석을 통한 적절한 항생제의 선택을 통해 광범위 항 생제의 사용을 가능한 줄이는 노력이 요구된다.

이전의 많은 연구에서 항생제의 사용량과 내성의 출현과의 직접적인 상관 관계에 대해 언급하였으며 부적절한 항생제의 사용이 항생제에 대한 내성을 유발할 수 있음을 경고하였다. ${ }^{14}$ 
항생제 사용량 증가는 선택적 압력으로 작용하여 내성의 발생 을 증가시킨다. Monnet 등 ${ }^{15}$ 은 macrolide, 3 세대 cephalosporin, fluroquinolon의 사용이 MRSA의 빈도를 증가시킨다 고 밝혔으며, Loeffler 등 ${ }^{16}$ 도 스위스의 3 차 병원을 대상으로 한 연구에서 piperacillin의 사용이 E. coli, P. aeruginosa의 piperacillin 내성과 양의 상관 관계가 있다고 증명한 바 있다. 또한 carbapenem의 처방이 감소하면서 carbapenem에 내성 인 Pseudomonas의 출현도 감소하였으며, vancomycin의 처 방의 감소가 $\mathrm{MRSA}$ 의 분리 빈도와 상관 관계를 보였다. ${ }^{17}$ 본 연구에서도 S. marcescens와 P. aeruginosa에서 piperacillin/ tazobactam 사용량과 내성률이 양의 상관관계가 있었으며, ciprofloxacin 사용량과 S. marcescens의 ciprofloxacin 내성, amikacin 사용량과 Acinetobacter의 amikacin 내성도 양의 상관관계를 보였다. 따라서 항생제 사용을 줄임으로써 항생제 내성을 감소시킬 수 있을 것으로 기대된다.

그러나 본 연구는 항생제 사용량과 항생제 내성의 상관 관계만을 분석하였으며, 항생제 내성에 영향을 미칠 수 있는 다른 인자들을 고려하지 않았다는 제한점이 있다. 추후 각 병원별로 환자의 중증도와 과별 특성, 원내 항생제 사용 방 침의 변화, 병원감염관리 체계의 변화 등을 고려한 연구가 필요할 것으로 생각한다. 또한 다양한 교육 활동과 지속적이 고 체계적인 항생제 관리 체계를 위한 적극적인 의료 전문 가들의 참여와 감시가 필요하며, 광범위 항생제의 사용을 자 제하고 배양 결과에 근거한 적절한 항생제의 사용을 위한 노력이 필요하다.

\section{알 림}

본 연구는 2007년도 전남대학교병원 임상의학연구소학술 연구비(CRI07073-1)에 의하여 연구되었음.

\section{References}

1. Cosgrove SE. The relationship between antimicrobial resistance and patient outcomes, mortality, length of hospital stay, and health care costs. Clin Infect Dis 2006;42(Suppl 2):S82-9.

2. Song JH, Jung SI, Ko KS, Kim NY, Son JS, Chang HH, et al. High prevalence of antimicrobial resistance among clinical Streptococcus pneumoniae isolates in Asia (an ANSORP study). Antimicrob Agents Chemother 2004;48:2101-7.

3. WHO, WHO Global Strategy for Containment of antimicrobial resistance. WHO/CDS/CSR/DRS/2001/2/EN, 2001

4. WHO, Antibiotic resistance: synthesis of recommendations by expert policy group. 2001

5. WHO, WHO collaborating centre for drug statistacs methodology. http://www.whocc.no/atcddd/

6. Kim DS, Kim NS, Jang SM. The study for trend of national antibiotic consumption. Infect Chemother 2006;38(Suppl 1):S1-28.

7. Jung SI, Park KH, Kwon KT, Ko KS, Oh WS, Chung DR, et al. Relationship between beta-lactam antimicrobial use and antimicrobial resistance in Klebsiella pneumoniae clinical isolates at 5 tertiary hospitals in Korea. Infect Chemother 2007;39:189-95.

8. Yoon YK, Kim MJ, Sohn JW, Park DW, Kim JY, Chun BC. Surveilance of antimicrobial use and antimicrobial resistance. Infect Chemother 2008;40:93-101.

9. Wisplinghoff H, Bischoff T, Tallent SM, Seifert H, Wenzel RP, Edmond MB. Nosocomial bloodstream infections in US hospitals: analysis of 24,179 cases from a prospective nationwide surveillance study. Clin Infect Dis 2004;39:309-17.

10. Lee KW, Kim YA, Park YJ, Lee HS, Kim MY, Kim EC, et al. Increasing prevalence of vancomycin-resistant Enterococci, and cefoxitin-, imipenem-, fluroquinolone-resistant gram-negative bacilli: a KONSAR study in 2002. Yonsei Med J 2004;45:598-608.

11. Lee HK, Kim CK, Lee J, Lee SH, Ahn JY, Hong SG, et al. Antimicrobial resistance of clinically important bacteria isolated from 12 hospitals in Korea in 2005 and 2006. Korean J Clin Microbiol 2007;10:59-69.

12. McGowan JE Jr, Tenover FC. Control of antimicrobial resistance in the health care system. Infect Dis Clin North Am 1997;11:297-311.

13. Du B, Chen D, Liu D, Long Y, Shi Y, Wang H, et al. Restriction of third-generation cephalosporin use decreases infection-related mortality. Crit Care Med 2003;31:1088-93.

14. Shalit L, Low M, Levy E, Chowers M, Zimhony O, Riesenberg K, et al. Antibiotics use in 26 departments of internal medicine in 6 general hospitals in Israel: variablility and contributing factors. $J$ Antimicrob Chemother 2008;62:196-204.

15. Monnet DL, MacKenzie FM, López-Lozano JM, Beyaert A, Camacho $\mathrm{M}$, Wilson R, et al. Amtimicrobial drug use and methicillin-resistant Staphylococcus aureus, Aberdeen, 1996-2000. Emerg Infect Dis 2004; 10:1432-41.

16. Loeffler JM, Garbino J, Lew D, Harbarth S, Rohner P. Antibiotic consumption, bacterial resistance and their correlation in a Swiss university hospital and its adult intensive care units. Scand J Infect Dis 2003;35:843-50.

17. Bantar C, Sartori B, Vesco E, Heft C, Saúl M, Salamone F, et al. A hospitalwide intervention program to optimize the quality of antibiotics use: impact on prescribing practice, antibiotic consumption, cost savings, and bacterial resistance. Clin Infect Dis 2003;37:180-6. 